Preprints of the

Max Planck Institute for

Research on Collective Goods

Bonn 2009/2

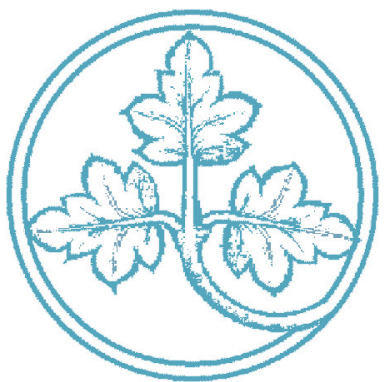

Experts and Decision

Making: First Steps

Towards a Unifying Theory of Decision Making in Novices, Intermediates and Experts

Britta Herbig / Andreas Glöckner

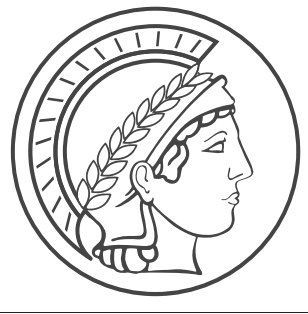




\section{Experts and Decision Making: First Steps Towards a Unifying Theory of Decision Making in Novices, Intermediates and Experts}

Britta Herbig / Andreas Glöckner

January 2009 


\title{
Experts and Decision Making: \\ First Steps Towards a Unifying Theory of Decision Making in Novices, Intermediates and Experts ${ }^{1}$
}

\author{
Britta Herbig $^{*}$ \& Andreas Glöckner ${ }^{* *}$
}

\begin{abstract}
Expertise research shows quite ambiguous results on the abilities of experts in judgment and decision making (JDM) classic models cannot account for. This problem becomes even more accentuated if different levels of expertise are considered. We argue that parallel constraint satisfaction models (PCS) might be a useful base to understand the processes underlying expert JDM and the hitherto existing, differentiated results from expertise research. It is outlined how expertise might influence model parameters and mental representations according to PCS. It is discussed how this differential impact of expertise on model parameters relates to empirical results showing quite different courses in the development of expertise; allowing, for example, to predict under which conditions intermediates might outperform experts. Methodological requirements for testing the proposed unifying theory under complex real-world conditions are discussed.
\end{abstract}

Keywords: Judgment and Decision Making, Expertise, Intermediate Effects, Parallel Constraint Satisfaction, Mental Representation

1 We thank Christoph Engel, Emanuel Towfigh, and Andrea Ahlgrimm for very helpful comments on earlier drafts of this paper.

* Correspondence concerning this paper should be addressed to: Dr. Britta Herbig, Institute and Outpatient Clinic for Occupational, Social and Environmental Medicine, Ludwig-Maximilians-University of Munich, Ziemssenstr. 1, D-80336 München, Germany, Phone: +49-89-5160-7695, E-mail: britta.herbig@med.unimuenchen.de

** Max Planck Institute for Research on Collective Goods, Bonn, Germany 
In everyday life, expertise and decision making are inseparably enmeshed with each other. With the exception of purely psychomotor areas, we expect that identified experts also make good judgments and decisions in their domain of expertise. When our car makes "funny" noises, we bring it to an expert mechanic and let him judge what to do. When we feel ill, we see an expert physician and let her determine what the problem is and what to do about it. Moreover, it is an increasingly common approach in politics, business, non-profit organizations and many other areas of public life to enlist expert commissions to advice and help decision makers in their task. However, there is a downside to this practice: First of all, how do we know that we are dealing with an expert mechanic, an expert physician or an expert consultant? And, even if we are able to identify an expert, does he or she really make the better judgments on which we can base our decision? The societal relevance of these questions can, for example, be observed in the growing unease about the practice of expert commissions in the area of politics and organizations. The CSU politician Peter Ramsauer (2000) termed this development "Kommissionitis" (see also Leersch, 2001) and laments that "all crucial questions for the future [...] are delegated to the responsibility of arbitrarily composed non-parliamentarian committees. The federal government [...] retreats into a moderating role and confines itself to the presentation of expertises and experts." (transl.) Recently, Sentker (2008) has commented on the results of an expert commission on expert commissions and concludes "Independence? Competence? Transparency? The three pages of the guideline to political consulting should become mandatory reading for politicians and scientists. So that self-evident demands finally become a matter of course." (transl.) So, in society there seem to exist simultaneously the notion that expert opinions are to be preferred over lay or novice opinions and, on the other hand, the fuzzy impression that it is not right to delegate important judgments and decisions to experts - especially when it comes to the backbone of societal life, the rules enacted by politics and enforced by law. This paper will not be able to solve this dilemma but we will try to outline an approach that might be useful to remedy some of the intriguing discrepancies in research on expertise, on the one hand, and judgment and decision making (JDM), on the other. At first, however, we will show that research has come up with some of the same intricacies and has yet to deal with the fundamental problems.

\section{Research on Expertise and JDM}

The most commonly acknowledged definition of expertise is that experts show high, outstanding, and exceptional performance that is domain-specific, stable over time, and related to experience and practice. Additionally, some authors regard the possession of knowledge as an essential part of expertise (cf. Sonnentag, 2000). However, the relationship between processes of JDM, on the one hand, and different levels of expertise, on the other, has up to now only been investigated sporadically (e.g., Chan, 1982; Ebbesen \& Konečni, 1975; Önkal-Atay, Yates, Şimga-Mugan, \& Ötzin, 2003). One reason for this lack of research might be that in the necessarily domain-specific investigation of expertise, JDM is just one aspect of many cognitive and affective processes that differ between laypersons or novices and experts. Moreover, it seems questionable whether there is something like expertise in JDM outside the realm of a specific 
domain. Or, as Yates and Tschirhart (2006) state, there are hardly satisfying answers regarding the question how to explain expertise in JDM or how to facilitate the development of such an expertise.

One marked exception to this deficit is Naturalistic Decision Making (NDM), a line of research that started in the beginning of the 1990s (Klein, Orasanu, Calderwood, \& Zsambok, 1993) as a deliberate counter movement to traditional paradigms of JDM research. NDM aims at investigating decision making in the real world. It defines ill-structured problems, uncertain dynamic situations, severe time-pressure and massive consequences for the decision maker as key factors for decisions under real-world conditions (for an overview see e.g., Ross, Shafer, \& Klein, 2006; Salas \& Klein, 2001). Consequently, NDM researches experts like military leaders, fire ground commanders or pilots, that is, judgments and decision making in domains in which the abovenamed conditions apply. The earliest and probably most influential model of decision making in this area is the "recognition-primed decision model" by Klein (1989). It starts with the assumption that experts possess a large repertoire of stored situation prototypes. These prototypes contain the type of situation, what to expect from the situation, suitable goals, typical courses of action, and relevant cues (i.e., information that has a predictive power for decision-relevant outcomes). If a situation is recognized as an instantiation of a prototype, it typically leads directly and without deliberation to action because the situation prototype is linked to a course of action that the expert already knows will work. However, if a situation is too unusual or too uncertain, a sequential mental simulation of particular potential courses of action takes place until a satisfying solution is found. Every action option is evaluated by itself and in a sequential order - a direct and demanding comparison of options against each other, such as it occurs in classical decision models, does not take place. As the authors of the recognition-primed decision model posit severe time-pressure as a situational constraint, this type of decision making seems plausible and empirical studies in respective domains indicate its validity (e.g., for military command and control officers, see Pascual \& Henderson, 1997; for offshore installation managers, see Flin, Slaven, \& Stewart, 1996; for electronic warfare technicians, see Randel, Pugh, \& Reed, 1996). Besides the indisputable merits of the NDM approach, it remains somewhat vague because no computational model is specified. Therefore, several issues remain unclear, such as the question what experts do in new situations and how far experience can be generalized. Do these mechanisms also apply to decision making in complex situations without severe time pressure?

Another area of research deals with the quality of experts' decisions and judgments (although not identical, both aspects are considered together since only little research deals explicitly with decisions). ${ }^{2}$ Shanteau (1992, p. 253) summarizes that "with some exceptions, the judgment and decision making literature paints a dismal picture of the ability of experts". He recaps studies

2 Note that in JDM research judgments (i.e., assessment of a decision-relevant aspect) are distinguished from (preferential) decisions which often are assumed to additionally entail a commitment to a certain course of action and to take into account individual preferences (Yates \& Tschirhart, 2006). In this paper, for the sake of simplicity and in line with influential related publications (e.g., Dougherty, Gettys, \& Ogden, 1999; Holyoak \& Simon, 1999; Klein, 1989), we will use the notion decision in the broader sense as selection of one out of several options (or a recommendation for the selection of an option) based on probabilistic judgment. 
that show expert judgments to lack reliability and validity, probabilistic judgments of experts to have deficiencies in coherence and calibration, and experts to make only use of few information in a simple linear way (for classic findings, see Meehl, 1954). A well-established explanation for this poor performance record states that experts often rely on heuristics, which in turn may lead to systematic biases (Kahneman, Slovic, \& Tversky, 1982). However, research from cognitive psychology shows a much more favorable view of experts' performance. Experts are superior to novices in nearly every aspect of cognitive functioning, from memory and learning to problem solving and reasoning (Anderson, 1981; Shanteau, 1992). Chi (2006a), Speelman (1998), and others report similar dichotomies in reviews of research findings (for a more detailed discussion, see below).

No less divergent than these results are the theoretical and empirical contributions on the question of different levels of expertise. A considerable number of terms from simple novice/experts distinctions to proficiency scales of up to seven different levels (e.g., Chi, 2006a, in adapting Hoffman, 1998, distinguishes between naïve, novice, initiate, apprentice, journeyman, expert, master) raises the problematic question of how to measure these different levels (cf. Sonnentag, 2000). Moreover, theories on the development of expertise vary greatly in their assumptions: there are theories proposing a discontinuity in the development of expertise (so-called intermediate effect, i.e., a decrease in performance on a medium level of experience, e.g., Patel, Arocha, \& Zhang, 2005; Witteman \& van der Bercken, 2007); theories that expect a performance plateau in the development of expertise that people can only overcome with deliberate effort (deliberate practice by Ericsson, Krampe, \& Tesch-Römer, 1993); and theories that assume a more or less continuous development of expertise (e.g., Dreyfus \& Dreyfus, 1986), sometimes with qualitative leaps (e.g., Benner, 1984).

To sum up, although studies in expertise and studies in JDM are fruitful and lively areas of research, a unifying theory of JDM on different levels of expertise is completely lacking. In the following sections, we will first outline parallel constraint satisfaction (PCS) models (Read, Vanman, \& Miller, 1997; Simon, 2004; Simon, Snow, \& Read, 2004) that, in our opinion, have the potential to integrate the different research areas and to act as a framework for modeling cognitive processes of JDM on different levels of expertise (see also Spellman, in press). In a second step, using existing model parameters, we will discuss findings from studies on expertise and derive hypotheses as to how a PCS approach could account for these results. Finally, we will discuss in greater detail studies by Witteman and van der Berken (2007), Boshuizen and Schmidt (1992) and Schmidt and Boshuizen (1993) on expertise development and outline more specific hypotheses concerning the structure of decision networks of experts, intermediates and novices. Moreover, we will outline how the PCS approach can account for the seemingly contradictory findings concerning decision performance and decision time on different levels of expertise. 


\section{Parallel Constraint Satisfaction Models of Decision Making}

Classical theories of decision making imply that decisions are made through a conscious deliberation of information (cf. Simon, 1955). It has been repeatedly shown that individuals do not always use the mathematically optimal strategy and show systematic deviations from rational behavior (e.g., Kahneman et al., 1982; Kahneman \& Tversky, 1982, 1984; Simon, 1956; Tversky \& Kahneman, 1974). Many current models of decision making posit that individuals possess a number of information integration strategies of different complexity that are used predominantly consciously and adaptively, taking into account specific properties of the situation (e.g., effortaccuracy trade-off, environmental structure; cf. Beach \& Mitchell, 1978; Gigerenzer \& Todd, 1999; Payne, Bettman, \& Johnson, 1988, 1993). Automatic processing got less attention in decision research for a long time (Kahneman \& Frederick, 2002; but see Busemeyer \& Townsend, 1993; Doherty \& Kurz, 1996; Dougherty, Gettys, \& Ogden, 1999; Epstein, 1990; Evans, 2008; Hammond, Hamm, Grassia, \& Pearson, 1987; Juslin, Winman, \& Hansson, 2007; Sloman, 2002). ${ }^{3}$ In contrast to these approaches, the PCS model of decision making (Glöckner \& Betsch, 2008b; for earlier accounts, see Holyoak \& Simon, 1999 and Thagard \& Millgram, 1995) assumes a primacy of automatic processes and ascribes deliberate processes (only) a supporting part for the optimization of decisions (see Figure 1). According to the PCS model, every decision starts with the perception of a decision problem. This leads to an automatic activation of a multitude of associated information that forms a temporally activated network (see Figure 2). Once this primary network is constructed, automatic consistency-maximizing processes operate towards establishing a consistent interpretation of activated information. Thereby different ways of interpreting the decision situation are weighed against each other, and the most probable interpretation is highlighted. This happens by way of a devaluation of information that does not support the dominant interpretation, and a simultaneous increase in the valuation of information that does. The process results in a mental representation that guides decision making. In many everyday situations, and especially in the decision making of experts, this proceeds completely automatically: a situation is perceived, a completely unconscious mental representation (primary network) is constructed and the favored option is chosen (see Figure 1). This process parallels the formation of a good "Gestalt" in perception, as already described by Wertheimer (1925, 1938) and other Gestalt-psychologists (cf. Holyoak \& Spellman, 1993).

3 Please note that automatic processes were very early considered in research on judgment (Brunswik, 1955; cf. Doherty \& Kurz, 1996), whereas they were mainly ignored in research on decision making (in the narrower sense). 


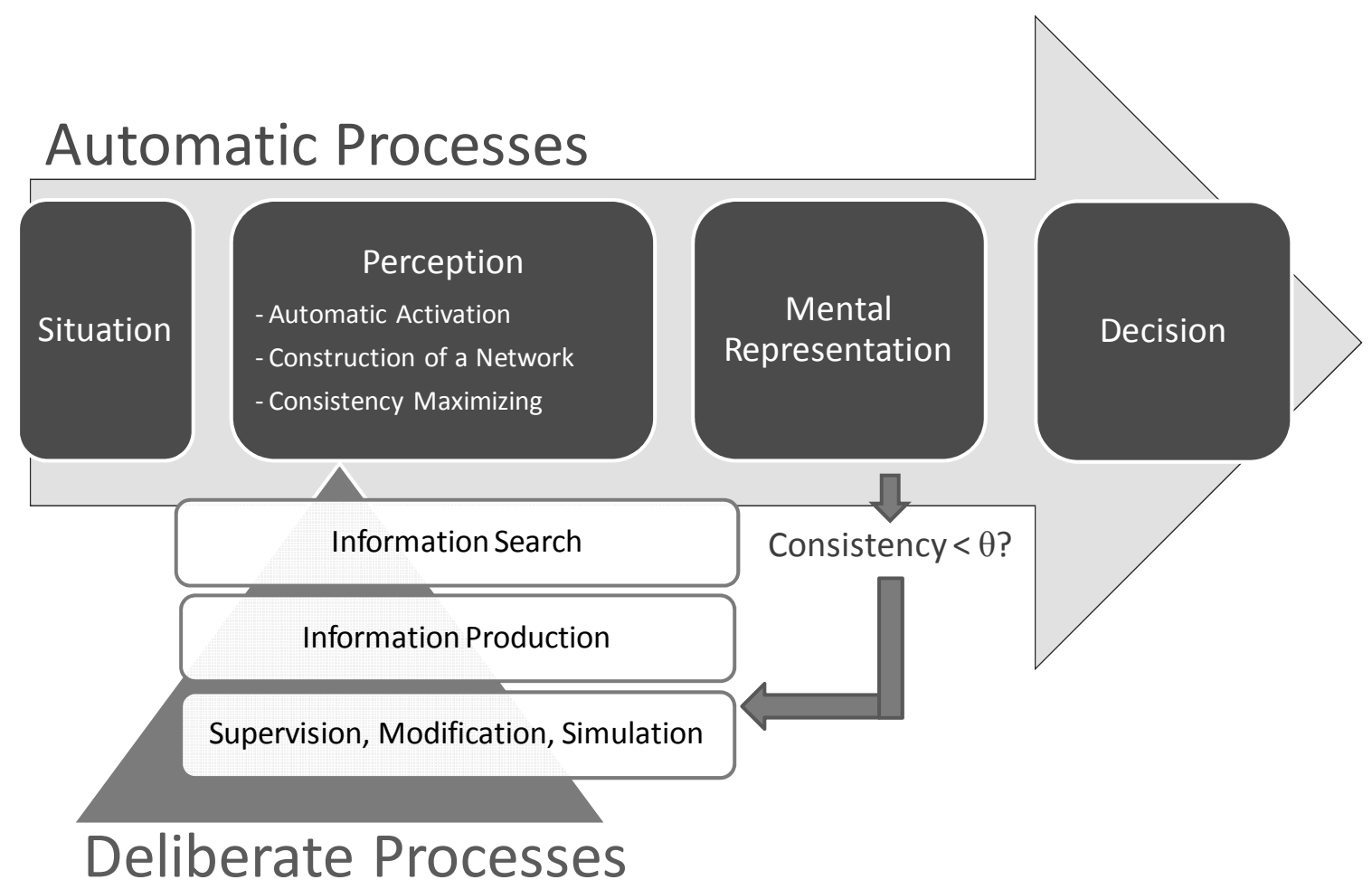

Figure 1. Parallel constraint satisfaction model of decision making (Glöckner \& Betsch, 2008b) process model

According to the PCS model, the automatic consistency-maximizing process in the primary network is at the core of every decision making. This process allows for a fast integration of a multitude of information. Only through this process is an extremely quick understanding of even the most complex situations and an adequate decision making possible. For reasons of capacity, an exclusive use of deliberate processes would not allow for such a fast reaction (cf. Payne et al., 1988). Deliberate processes (i.e., conscious reflection) are only employed if an adequate, good interpretation regarding the importance of a situation cannot be found. That is, deliberate processes are activated if the consistency of a resulting mental representation is below a threshold $\theta$. Only in that case, a superordinate secondary network is activated that contains potential deliberate "construction mechanisms" which in turn can support the consistency maximization in the primary network. Deliberate construction mechanisms in the secondary network are again selected through PCS processes. In the simplest case, conscious processes are used to gather or produce (additional) information - e.g., on the basis of mathematical analyses - and therefore to enrich the network. Moreover, deliberate processes can be used for a temporal change of the network structure, for example to simulate different interpretations of the situation (cf. Betsch, 2005).

According to the PCS model, the representation of a decision situation is modeled as a temporarily activated network (see Figure 2). This network is composed of nodes and inhibitory or excitatory links between these nodes. Activation is spread through these links, which can differ in strength. The nodes of the network represent options and cues that can reach different activation 
levels. All links are bidirectional, which means that cues not only facilitate (or inhibit) options, but also vice versa. The strength of the relation between nodes is represented by weights. Excitatory (inhibitory) links between cues and options represent a positive (negative) prediction of cues for options. The general validity node activates the network. The strength of the excitatory links between the general validity node and the cues indicate the initial validity of the cues and the spread of activation in the network is simulated by an iterative updating function that maximizes consistency under the given constraints. A sigmoid activation function is used to simulate spreading activation in the network (McClelland \& Rumelhart, 1981; Rumelhart \& McClelland, 1982). This algorithm maximizes consistency and, after a certain number of iterations, leads to a balanced state in which activations stop changing. In other words, activation spreads in an iterative process, whereby the activation level of the nodes that represent options and cues is jointly modified according to the underlying structure of interdependencies. When a stable activation level is reached, it is then compared with the targeted consistency threshold $\theta$ (see Figure 1). The final activation of the option nodes represents their attractiveness (i.e., individuals' tendency to choose the respective option) and the final activation of the cue nodes represents the a-posteriori cue validities (i.e., individuals' subjective estimation of the validity of the cue after consistency maximizing). In the stable state, one option will usually dominate the other options and will be highly activated. Cues that support this option will be highly activated, too, whereas cues that oppose this option will have a lower activation (for details, see Glöckner \& Betsch, 2008b).

\section{How to Capture Expertise in Parallel Constraint Satisfaction Models}

The different levels of expertise (e.g., Chi, 2006a) could influence decision making according to PCS in two ways: They may lead to different mental representations (i.e., differences in the structural model, Figure 2) and/or they may affect the parameters of the consistency maximizing process (i.e., differences in the process model, Figure 1). Before discussing these differences in greater depth we first want to summarize how other decision models might capture expertise.

Although decision models are usually not concerned with questions of expertise development, some of them allow deriving predictions for this process. Thereby it is useful to differentiate between a) multiple strategy models, which assume that individuals select between different decision strategies (e.g., Gigerenzer \& Todd, 1999; Payne et al., 1988), and b) single strategy models, which assume that always the same strategy is applied but fed with different input information (e.g., Brunswik, 1955; Busemeyer \& Townsend, 1993; Glöckner \& Betsch, 2008b; Newell, 2005). Assuming that people apply different strategies (i.e., following multiple strategy models) that mainly rely on deliberate calculations, repeated training will lead to less computational errors and quicker decisions. Furthermore, feedback learning could decrease the prevalence of strategies that lead to wrong solutions and increase the application of successful ones (Rieskamp \& Otto, 2006).

Single strategy models assume that there is no selection between strategies hence expertise has to be explained differently. As stated by the Brunswikian lens model (Brunswik, 1955) and social 
judgment theory (see Doherty \& Kurz, 1996, for an overview), experience and feedback should over time lead to better judgments because people learn how to weight different cues to predict specific outcomes (i.e., people might improve their adjustment of cue validities to the structure of the environment). Experience could also lead to the development of routines of option choices, which are selected in similar situations without further deliberation (Betsch, Haberstroh, Glöckner, Haar, \& Fiedler, 2001). Similarly, according to the recognition-primed decision model (Klein, 1989) with practice in a specific domain people will memorize an increasing amount of successful solutions to specific problems which could later on be used to select appropriate actions (Klein, 1989; see also Dougherty et al., 1999).

Thus, multiple strategy models would explain differences between expert decision makers and novices by more accurate strategy application and better strategy selection, whereas the single strategy models explain differences by increasing numbers of stored instances of experience or better calibration of cue validities to the environment that are fed into the unique information integration process. The PCS approach allows specifying and extending the later view.

As introduced above, PCS models follow a single strategy approach and assume that decisions are based on automatic consistency-maximizing processes that operate on (different) mental representations. According to the model there should be no differences between experts and novices in the general mechanism for information integration (i.e., consistency-maximizing). However, we argue that depending on the level of expertise ${ }^{4}$ there should be differences in the modeldetermining parameters and input variables. In this paragraph, we will build on findings from expertise research to derive specific predictions how expertise can be captured in PCS models. Figure 2 gives an overview along which we will argue. Considerations one to three concern differences in the structural model and considerations four to six relate to the process model.

4 In research on expertise, one can differentiate between experience and excellence conceptualizations of expertise. Whereas the experience conceptualisation reckons the length of time working in a domain as an indicator for expertise, the excellence conceptualization looks at the performance of a person in a domain independent of experience. The following reported differences are - unless otherwise noted - results from studies with both conceptualizations. 


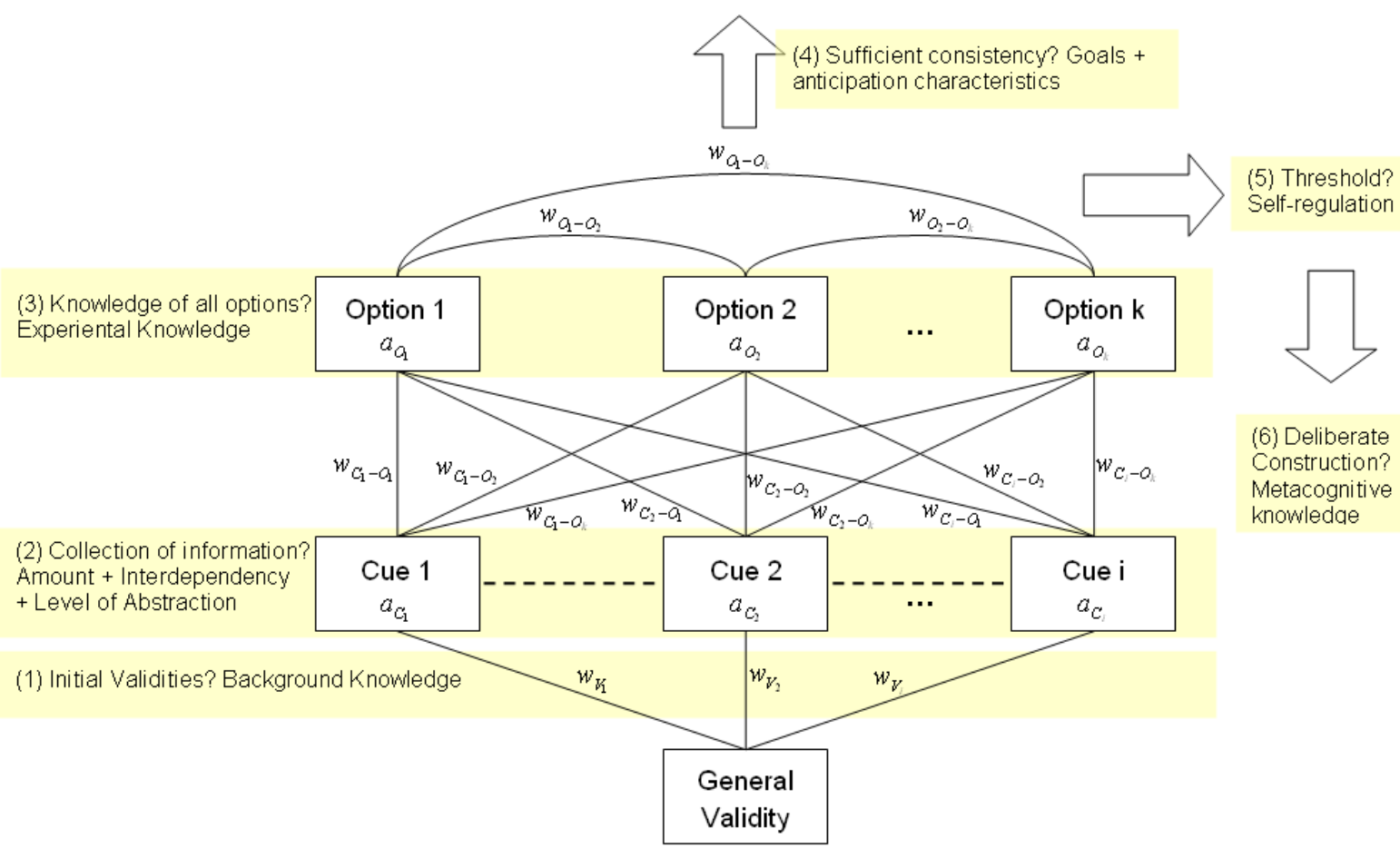

Figure 2. PCS and its relation to expertise - structural model.

Initial cue validities. First, because of their experience and better knowledge of the domain experts should ascribe more adequate initial validities to cues than non-experts. This assumption rests upon the quite clear empirical results on the adequateness of experts' knowledge. Experts possess "better" knowledge (Sonnentag, 2000). Their knowledge is inter alia more complete (Curtis, Krasner, \& Iscoe, 1988; Schaper \& Sonntag, 1998), contains less incorrect parts (Wiedemann, 1995), and is better integrated (Herbig \& Büssing, 2003; Herbig, Büssing, \& Ewert, 2001; Sujan, Sujan, \& Bettman, 1988). Very often it exists in a procedural (Sonnentag, 1998), automated (Schneider, 1985) or implicit form (Herbig, 2001; Wagner \& Sternberg, 1985), respectively. That is, experts should be able to rate cues much better regarding their validity for certain decision options than non-experts because of their markedly bigger and more fitting knowledge base.

Number of cues, interrelation and abstraction level. Second, what information (cues) do experts and non-experts collect and use in their PCS network? This question relates to the amount of cues and their interrelations as well as to their level of abstraction or integration, respectively. Empirical results from expertise research differ between experienced persons, on the one hand, and excellent performers, on the other (see footnote iii). Experienced persons usually spent more time searching for information while dealing with complex problem-solving tasks than inexperienced persons (e.g., Schaub \& Strohschneider, 1992; Voss, Greene, Post, \& Penner, 1983). Excellent performers, however, spent less or the same amount of time on activities of problem comprehension than moderate performers (e.g., Koubek \& Salvendy, 1991; Schaper \& Sonntag, 1998). At the same time, these results for problem-solving tasks do not generalize to decision 
tasks. For example, Kirschenbaum (1992) and Wiggins and O'Hare (1995) showed that experienced as well as excellent performers spent less time on problem comprehension when confronted with decision tasks. However, although experts do not use more time for the collection of information, a detailed analysis by Elstein, Shulman, and Sprafka (1978) on expertise in medical diagnostics revealed that experts indeed gathered more information in this time than non-experts. That is, experts worked more efficiently. In addition, experienced as well as excellent performers exhibit a higher degree of knowledge integration and the ability to switch from general, abstract information to specific and concrete information while searching for clues (e.g., Bédard \& Mock, 1992; Klemp \& McClelland, 1986; Wiedemann, 1995). By means of "scripts" that comprise key stimuli, experts can quickly focus on the essential characteristics (Hershey, Walsh, Read, \& Chulef, 1990). Via this process, large bundles of cues are used as one piece of information. There are several similar concepts that may explain the bigger amount of employed information in the same or smaller period of time used for the collection of information. These are, for example, encapsulated knowledge 5 (e.g., Boshuizen \& Schmidt, 1992; Gruber, 1999); the extensively proven chunking ${ }^{6}$ of information in short-term memory by experts (e.g., Chase \& Simon, 1973a, 1973b; Egan \& Schwartz, 1979; Ericsson \& Lehmann, 1996; Glaser \& Chi, 1988; Lesgold, Rubinson, Feltovich, Glaser, Klopfer, \& Wang, 1988; Simon \& Chase, 1973) and its advancement to the concept of long-term working memory ${ }^{7}$ by Ericsson and Kintsch (1995). Taken together, it seems plausible that the PCS networks of experts represent a bigger amount of information that sometimes is more integrated, more abstract and more interdependent than the information in PCS networks of non-experts. Moreover, experts are able to perceive very subtle information and blend them into a whole (e.g., Crandall \& Getchell-Reiter, 1993) without being able to verbalize how they arrived at their understanding of the situation (Benner, 1984).

Knowledge of solutions / options. Third, analogous to the concept of objective and subjective latitudes in action-regulation theory (e.g., Hacker \& Matern, 1980; Oesterreich \& Volpert, 1987), experts and non-experts should differ in their knowledge of the potential decision options. Nonexperts might only know a portion of the actual existing options and their subjective latitude could be smaller than the objective one. Experts on the other side should have a mental representation in which subjective and objective latitude match. That is, the completeness of knowledge, the more precise representation of the domain and the faster retrieval of this knowledge (Alexander, 2003) should lead to the effect that even in automatic processing with PCS experts take (virtually) all decision options into account. To the best of our knowledge, there are no empirical studies regarding this question from the perspective of decision making research (except for the above mentioned "recognition-primed decision model" by Klein, 1989). However, looking for example at the well-documented domain-specific cognitive strategy of „forward reasoning“ (e.g.,

$5 \quad$ Encapsulation: “...the progressive subsumption, or packaging, of lower level concepts and their relations in an associative net under a limited number of high-level concepts with the same explanatory power, which results from repeated application of knowledge to similar situations" (Schmidt \& Boshuizen, 1993, p. 347)

6 Chunking: In order to circumvent or expand the $7 \pm 2$ limitations of short-term memory, bits of information are grouped (chunked) into larger units.

7 Long-term working memory: Specialised encoding and retrieval structures allow for the circumvention of the "bottleneck" of short-term memory in processing information by storing directly in and retrieving directly from long-term memory. 
in physics: Larkin, McDermott, Simon, \& Simon, 1980; in medicine: Patel \& Kaufman, 1995), it becomes clear that this expert strategy only leads to good results if all options are represented in the processing network.

Taken together, these three influences of expertise concern differences in the structural models. However, there could also be differences in process parameters. Specifically, expertise could influence the decision threshold $\theta$ which determines whether an option is chosen or deliberate processes are activated. For the sake of clarity, we will discuss first the influence of expertise on the thresholds and how it could lead to overconfidence. Afterwards the related question of the activation of deliberate processes will be discussed.

Decision threshold. As discussed above, PCS mechanisms maximizing consistency in a network. The processing of information via the primary network stops if an asymptotically stable interpretation is found. The simulation of this termination of processing can be described mathematically as a state in which the activation in the network has not changed in several cycles (Glöckner \& Betsch, 2008b). Then, the final consistency is compared with a consistency threshold. If the finally reached consistency lies above this threshold, the option with the highest activation will be chosen (if consistency is below the threshold, deliberate processes are activated; see below). However, it remains unclear which factors determine the level of consistency (i.e., threshold) a person finds satisfactory. Within research on expertise it is conceivable that width of planning and goals play an important role in determining which level of consistency is acceptable. Goals are at the same time resolve and anticipation, that is, they motivate to act and anticipate the consequences of this action. Against this background, goals represent the relevance of a decision which in turn should adjust the threshold of an acceptable level of consistency (e.g., Betsch, 2005). Results from expertise research show that experts in general work in a more goalorientated fashion (e.g., Hershey et al., 1990; Schenk, Vitalari, \& Davis, 1998) and that excellent performers often prioritize long-term goals (e.g., Hacker, 1992; Hacker \& Vaic, 1973). This trend can also be found in the area of planning behavior; however, especially in unstructured, complex situations experts use a mixture of planning activities (e.g., Leithwood \& Steinbach, 1995), on the one hand, and opportunistic ${ }^{8}$ procedure (Gilhooly, McGeorge, Hunter, Rawles, Kirby, Green, \& Wynn, 1997; Müller, Herbig, \& Petrovic, 2007; Müller et al., in press; Visser, 1994), on the other. Taken together, these results may hint at a higher consistency threshold necessary for experts to make a decision. Moreover, this assumption is in line with another result from expertise research: Experts often rely too much on their capabilities and in some situations they display overconfidence in their decisions (e.g., Chi, 1978; Englich \& Mussweiler, 2001; Glenberg \& Epstein, 1987; Shanteau, 1992). If experts indeed need a higher degree of consistency in their network before deciding (i.e., have a higher consistency threshold), the finally reached attractiveness should differ more between options than with a lower consistency thresh-

8 In this context the term 'opportunistic procedure' describes that experts while solving a problem use every possible source of information as a starting point for further proceeding. 
old. This, in turn, will lead to a higher confidence in the given judgment and a (too) high estimation of related cues validities.

Initiation of deliberate constructions. There are also results from expertise research that are informative concerning the question when deliberate constructions are activated (i.e., activation of a secondary network). Wagner and Sternberg (1985) (see also Büssing, Herbig, \& Ewert, 2001) demonstrated that experts have more procedural and more implicit knowledge (in the sense of tacit knowledge Polanyi, 1966). This in turn might indicate that it takes more time for experts to initiate deliberate constructions because the adequate and pronounced automatic processes "assert" themselves. Conversely, the same study showed that not only domain-specific knowledge differs between good and poor performers, but also those parts of procedural knowledge that relate to metacognition and self-regulation. Moreover, it is a well documented fact that experts in general hold more metacognitive knowledge than non-experts (e.g., Chi, Glaser \& Rees, 1982; Eteläpelto, 1993; Lind \& Sandmann, 2003; Sonnentag, 1998). More declarative and more procedural meta-knowledge then might lead to a lower threshold for initiating deliberate constructions in experts. That is, experts should have a better understanding of their own automatic processes so that difficult and unsuccessful consistency-maximizing processes could be aborted at an earlier time.

Taken together, from a PCS perspective, differences between experts and non-experts in situations with complex informational states can be summed up as follows:

- In real-world situations, PCS networks of experts should contain more and/or other cues as well as more and/or other options than the PCS networks of non-experts.

- Cues in the PCS networks of experts have a higher level of aggregation regarding the organizing principle of content as well as regarding the size of chunks.

- Initial cue validities are more adequate in experts' PCS networks than in networks of non-experts.

Since it is not quite clear which background variables do exert an influence (goals, procedural knowledge, metacognition, amongst others), we assume on a weaker theoretical basis:

- The threshold for stopping the consistency-maximizing primary process should be higher for experts than for non-experts. That is, experts should require a higher consistency in their network before coming to a decision.

- At the same time, the threshold for initiating deliberate constructions, that is, the construction of a secondary network, should be lower for experts than for non-experts, meaning that experts should start deliberate processing earlier than non-experts. 
Up to now, we looked at differences between experts and non-experts. In the next section, we will describe in greater detail how PCS can account for findings concerning different developmental stages of expertise (i.e., novices, intermediates and experts).

\section{Novices, Intermediates and Experts - Decision Making on Different Levels of Expertise}

As outlined above, theories on the development of expertise vary greatly in their assumptions on performance on different stages of expertise. One puzzling problem seems to appear at an intermediate level of expertise. In studies contrasting novices, persons at an intermediate level of expertise, and experts, some researchers find a decrease in performance on a medium level; that is, intermediates perform worse than experts and novices (e.g., Patel, Evans, \& Groen, 1989; Witteman \& van der Bercken, 2007), whereas others show intermediates doing better than novices and experts (e.g., Schmidt \& Boshuizen, 1993) (for a discussion of these divergent results on the so-called 'intermediate effect', see, for example, Williams \& Noyes, 2007). To consider reasons for these differences in terms of PCS models we will first sketch three of the respective studies.

Witteman and van der Bercken (2007) studied the assessment performance of psychodiagnosticians in ten written and abbreviated cases from the DSM-IV case book (Frances \& Ross, 2001). The participants were required to give the DSM diagnostic classification. The authors differentiated theoretically and empirically between novices with zero to one year of experience, intermediates with up to 17 years' experience and very experienced clinicians (experts) with 18 years and upwards of experience. Witteman and van der Bercken argue that the very broad range of intermediates was used to mirror the fact that diagnostic classification is only a subtask in clinical practice, therefore not occurring as often as other tasks, which in turn should lead to less experience with this task. The cut-off value of 18 years represents the doubling of the conventional "expertise value" of nine to ten years in a certain domain (e.g., Feltovich, Prietula, \& Ericsson, 2006). As expected, the authors found an intermediate effect in the numbers of correct classifications: A cubic function fitted the data best. Intermediates performed worse than both novices and experts. However, one unexpected result occurred: looking at decision times, intermediates were significantly faster than both novices and very experienced clinicians. The authors tentatively interpret this as a result of the experts being aware of potential complexities and more possible diagnoses than intermediates, thus needing longer to think about diagnostic questions.

In studies undertaken in the domain of medicine, Boshuizen and Schmidt (1992) explored the role of biomedical knowledge on the diagnosis of clinical cases and assessed the effect of different levels of expertise on clinical case recall (Schmidt \& Boshuizen, 1993). In their first study, they classified the four participants from novice $\left(2^{\text {nd }}\right.$-year medical student $)$, intermediate $1\left(4^{\text {th }}-\right.$ year medical student, nearly finished with preclinical training), intermediate 2 ( $5^{\text {th }}$-year medical student, finished with internships in primary care and internal medicine) to expert (family physician with four years of experience). The task was to think aloud while being sequentially presented with information on a clinical case and to deliver a differential diagnosis at the end. The 
thinking-aloud protocols were then segmented into propositions which were coded as either biomedical or clinical. Results showed a monotonous decrease in the application of biomedical knowledge from over $50 \%$ in the novice's protocol to less than $10 \%$ in the expert's protocol. Boshuizen and Schmidt (1992) argued that three different explanations for this might be possible: First, with growing expertise biomedical knowledge becomes rudimentary; second, biomedical knowledge becomes inert, and third, in the development toward expertise biomedical knowledge becomes encapsulated in clinical knowledge. To test for these explanations, in a second experiment 20 participants in the respective levels of expertise completed the task from study 1 but were additionally asked to describe in writing the pathophysiological processes underlying the case. In data analysis, think-aloud propositions and post-hoc propositions were matched and the relation between the matched arguments classified as either identical or abbreviated. Results showed that the application of biomedical knowledge in the course of expertise development first increases and later decreases again. That is, in contrast to Witteman and van der Bercken (2007), an inverted U-shaped function was found. Moreover, the authors were able to demonstrate that this decrease from intermediate to expert level was not due to decay or inertia but to the encapsulation of biomedical knowledge in clinical knowledge. In a second set of studies, Schmidt and Boshuizen (1993) tested for an intermediate effect that also consistently produced an inverted U-shape form across expertise levels: The free recall of case relevant materials (e.g., Claessen \& Boshuizen, 1985; Muzzin, Norman, Feightner, \& Tugwell, 1983). Experiment 1 included 120 participants (health science students as laypersons, $2^{\text {nd }}-, 4^{\text {th }}-$ and $6^{\text {th }}$ year medical students as different level intermediates, and internists with at least 2 years of experience as experts). Subjects had to read case materials under three different time constraints, recall the information and give a diagnosis. Although the number of accurate diagnosis covaried significantly with expertise and processing time had an overall effect on diagnostic accuracy, the free recall of case material once again revealed a significant quadratic component. That is, $2^{\text {nd }}$-, $4^{\text {th }}$ - and $6^{\text {th }}$-year medical students (intermediates) recalled considerable more case information than laypersons and experts. In experiment 2, 80 persons participated from the same subgroups as in experiment 1 . With a priming paradigm, prior knowledge was either partially or fully activated. Again, diagnostic performance was strongly linearly related to expertise and a significant cubic intermediate effect on recall was found. Moreover, Schmidt and Boshuizen (1993) could demonstrate that among students, the free recall of a clinical case is causally determined by the amount of activation of pathophysiology knowledge, whereas among clinicians it is not. In light of their different experiments, the authors conclude that superior diagnostic performance of experts cannot be explained by a more extensive processing of a case but is based on knowledge structures that are qualitatively different from those of advanced students, namely, encapsulated knowledge. In addition, the results from free recall showed that experts subsumed a lot more propositions in encapsulated form than intermediates and were therefore able to use most of the case information without actually verbalizing it.

Taken together, the results from Witteman and van der Bercken (2007), Boshuizen and Schmidt (1992) and Schmidt and Boshuizen (1993) reveal some interesting features of intermediate and expert performance (although one has to bear in mind that the respective subgroups of expertise 
were operationalized quite differently). First of all, Witteman and van der Bercken (2007) found a disadvantage of intermediates over novices and experts in psychodiagnostic classification, whereas the latter authors found a linear positive relationship between diagnostic accuracy and expertise. Secondly, intermediates in the Witteman and van der Bercken study were significantly faster in their decisions than both novices and very experienced clinicians. In the study from Schmidt and Boshuizen (1993), the experimentally manipulated processing time of case material led to a significant quadratic effect of expertise; that is, with a longer processing time intermediates recalled a higher number of propositions than both the novices and experts. Moreover, the recall performance of experts was not affected by different processing times. And, last but not least, processing time did not influence the positive linear relationship between diagnostic accuracy and expertise. Actually, experts performed even better under high time constraints, although this effect did not reach significance.

Against the background of these findings, a model of decision making on different levels of expertise has to be able to account for the obviously contradicting effects that intermediates sometimes perform a) worse than novices and experts, b) better than novices but worse than experts or c) better than novices and experts. Furthermore, such a model has to explain why novices and intermediates are sensitive to time constraints but experts are not. Correspondingly, a model on decision making and expertise has to be able to explain the differences between different levels of expertise and it has to be able to predict under which circumstances which type of difference will occur. According to the classic decision models introduced above, there should be a monotonically increasing performance and decreasing decision time with increasing level of expertise. With growing experience, individuals should select and apply strategies quicker and with fewer errors (cf. Payne et al., 1988); they should select more appropriate strategies (Gigerenzer \& Todd, 1999; Rieskamp \& Otto, 2006); there should be more prototypes which (under the assumption of representative sampling) will provide better, more differentiated and quicker solutions to decision problems (Klein, 1989) and finally the calibration of cue usage to the cue validities in the environment should improve (Doherty \& Kurz, 1996). Thus, these decision models can only account for findings with intermediates being better than lay persons but worse than experts (i.e., (b)). In contrast, as we already suggested, the presented PCS model is able to account for the more differentiated findings. We will outline this claim in the following, based on the PCS experts - hypotheses derived above.

The main source of differences between novices, intermediates and experts is the mental representations underlying their decisions. Figure 3 depicts a grossly simplified picture of the potential differences in these networks. Based on the empirical results regarding information search in novices and experts, we propose that the networks of experts contain more cues than the networks of intermediates, which in turn contain more cues than the networks of novices. Moreover, experts' networks include links of different strength between cues (interdependencies), whereas networks of intermediates and novices do not. In addition, experts' and intermediates' networks comprise cues for different options, whereas the cues in the network of novices strongly support one option. And, finally, due to the differences in background knowledge and experience, the 
initial cue validities vary between the three groups. The sketchy representation in Figure 3 highlights the prominent point of divergence in the results of intermediate performance:
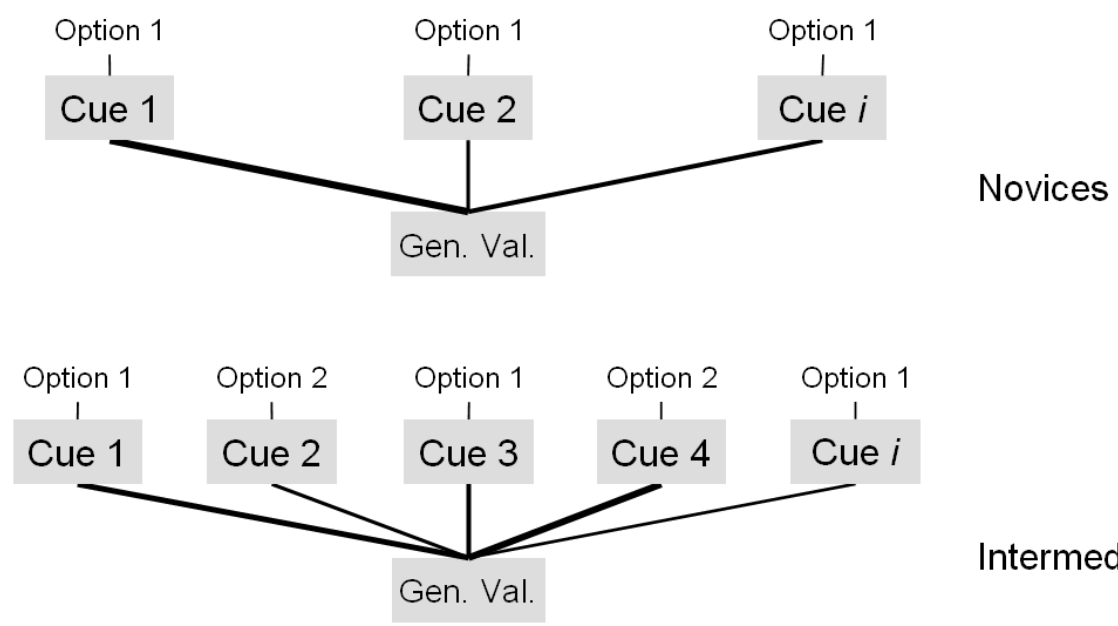

Intermediates

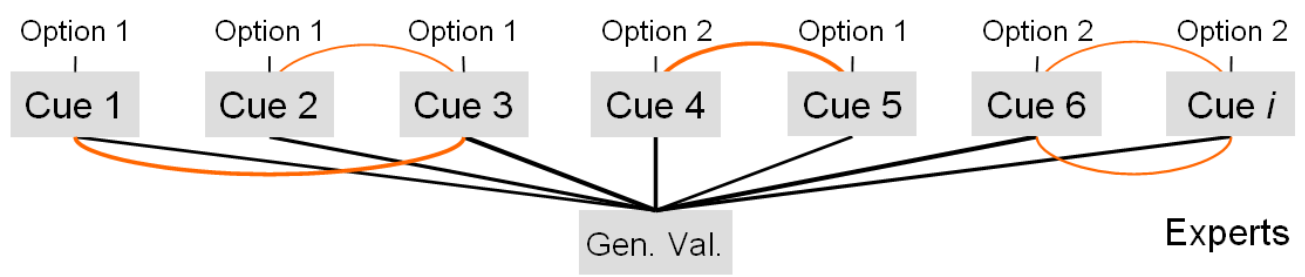

Figure 3. Schematized representation of parts of the PCS model for experts, intermediates and novices (strength of lines $=$ size of cue validities resp. strength of interdependency).

Depending on the accuracy of the initial cue validity, intermediates might reach correct decisions quite fast; but, even more importantly, performance that requests the recall of single units of information is likely to be good to very good for intermediates as they know enough about the domain to structure the information, but have not yet developed interrelating links between cues. Moreover, the knowledge base of intermediates should contain a lot of theoretical knowledge that is not yet integrated with experience-based knowledge. Under certain circumstances, for instance when a problem can be represented adequately by means of everyday knowledge, this in turn might lead to inferior performance even in comparison to novices or lay persons. Experts on the other side should store (and use) information in a chunked form (see, e.g., Chase \& Simon, 1973a, 1973b; Egan \& Schwartz, 1979; Ericsson \& Lehmann, 1996; Glaser \& Chi, 1988; Lesgold et al., 1988; Simon \& Chase, 1973; in terms of Schmidt \& Boshuizen, 1993: encapsulated knowledge), which might bring about worse performance in the recall of single units. This disadvantage, however, turns into an advantage under time constraints: Due to the interdependencies of cues, experts might be able to process a whole lot more information in the same time period novices and intermediates need to handle only a few cues. Chunking of information, as evidenced in experts' performance, might function in the case of parallel constraint satisfaction processing analogously to the "constrained basic-level malleability view" proposed by Johnson and Mervis (1997) in the area of categorization. These authors demonstrated that in the course of 
expertise development the universal basic level of categorization might shift to more specific sub-basic levels without losing its privileged status. These shifts depend on acquired knowledge, goals and domain and therefore allow for different categorizations in different situations. Along these lines, it seems plausible that chunks in experts PCS networks can take on different forms: They may act as a single processing unit, may play the role of gateway to highly interconnected background knowledge, or may still function as separate information units exhibiting or inhibiting each other depending on task constraints.

Taken together, the differences in structure and content of the PCS network determines the performance in decision making of novices, intermediates and experts. To investigate the proposed hypotheses empirically, a number of methods might be necessary. For instance, to understand which information is searched for and used on different levels of expertise, a nonreactive method like Active Information Search (Huber, 2007; Huber \& Huber, 2008; Huber, Wider, \& Huber, 1997) or Eye Tracking (e.g., Pomplun, Richter, \& Velichkovsky, 1996) might be useful; to make the chunks of experts accessible free recall (e.g., Chi, 2006b; Hoffman, 1987; Hoffman, Shadbolt, Burton \& Klein, 1995) as an established method in memory research could be useful; and to get a first glimpse at the underlying mental representation, methods for the elicitation and explication of knowledge (e.g., Büssing \& Herbig, 2003; Gaines \& Shaw, 1993) could be employed. We intend to use a combination of these methods in forthcoming research.

\section{Discussion}

Expertise research shows quite differentiated or even contradicting results on the abilities of novices, intermediates and experts in general, as well as on their performance in decision making tasks specifically. A unifying theory of decision making has to be able to account for these findings. Classic models of decision making, such as the multiple- and single-strategy models outlined above, are based on learning mechanisms and would predict (more or less) monotonic increases in decision making performance. However, this prediction is at odds with the results from expertise research. We could show that another approach to decision making, PCS, which also postulates a single strategy model (namely, processes of automatic consistency maximizing), is much better prepared to explain the puzzling results. However, a caveat is necessary: Although we propose differences in the structure of the primary networks of people on different levels of expertise, current PCS models do not explain the development of these mental representations in the course of expertise. Other theories might be better equipped to do so (e.g., Anderson, 1992; Anderson, Matessa \& Lebiere, 1997; for an overview see Hatano \& Inagaki, 2000). Nevertheless, as we aimed to show, they provide a useful framework to model the difference in decision making given existing differences in mental representations.

Although the literature overview, the outlined PCS model, and the proposed hypotheses are first steps towards a unifying theory of decision making on different levels of expertise, a lot of empirical testing has to be done before an evaluation of the proposed model can take place. One of the most important questions in this research will be how to deal with the complexity of real- 
world decision situations. As outlined by Glöckner and Betsch (2008b) it is possible to simulate some of the core assumptions with networks basing on the algorithm by McClelland and Rumelhart (1981). However, this will only be a starting point for tracing the potential complexity faced by every one of us each day.

The parallel constraint satisfaction approach provides an alternative to current interpretations of the bounded rationality approach (Simon, 1955; 1982) which assume that people use mainly simplifying strategies to reduce complexity while still reaching comparably good decisions (Gigerenzer \& Todd, 1999). In contrast to this view, findings indicate that the majority of people make decisions that follow a complex weighted compensatory integration of information (e.g., Bröder, 2003; Glöckner, 2007) and are based on automatic processing (Glöckner \& Betsch, 2008a; 2008c). Performance of experts in complex situations (e.g., Ericsson, Charness, Hoffman, $\&$ Feltovich, 2006; Sonnentag, 2000 for an overview), too, suggests that in real world situations more complex decision strategies are used, but these proceed often automatically, unconsciously or implicitly and therefore bypass an overload of the cognitive system (Glöckner, 2008; Herbig, 2001). Representative and ecologically valid situations (e.g., Winkel, 1987) from the respective domains of expertise are necessary if one attempts to understand the processes that allow novices, intermediates and experts to deal with the vast amount of information and knowledge necessary to make a decision (cf. Ericsson \& Charness, 1994; Shanteau, 1992).

Getting back to the question, raised at the beginning, whether "Kommissionitis" is a good thing or a bad thing, the answer regarding decision making might be "it depends". On the basis of theoretical assumptions of parallel constraint satisfaction models and the empirical results of expertise research, it seems reasonable to assume that experts indeed make better judgments and decisions than lay persons most of the time. However, looking at an intermediate level of expertise this assumption becomes somewhat less unambiguous. The degree to which the mental models capture reality should differ between novices, intermediates and experts. Yet, in order to gain an understanding of the contents of these models qualitative research is necessary in addition to the aforementioned testing of hypotheses. A combination of those methods permits not only conclusions about the proposed model-inherent differences but - together with characteristics of the decision task, the decision itself and its quality - also a first approach to socio-political relevant themes. This could, for example, be improvements in the training of professional decision makers or even changes in organizational structures or procedures to ensure optimal conditions for decision making. Moreover, the results of such an approach would help to predict under which circumstances experts make good decisions and under which conditions novices and/or intermediates also reach good or even better decisions. Thus, different methodological approaches will help to determine on which variables "it depends". 


\section{References}

Alexander, P. A. (2003). Can we get there from here? Educational Researcher, 32 (8), 3-4.

Anderson, J. R. (1981). Cognitive skills and their acquisition. Hillsdale, NJ: Erlbaum.

Anderson, J. R. (1992). Automaticity and the ACT* theory. American Journal of Psychology, $105,165-180$.

Anderson, J. R., Matessa, M., \& Lebiere, C. (1997). ACT-R: A theory of higher level cognition and its relation to visual attention. Human-Computer Interaction, 12(4), 439-462.

Beach, L. R., \& Mitchell, T. R. (1978). A contingency model for the selection of decision strategies. Academy of Management Review, 3, 439-449.

Bédard, J., \& Mock, T. J. (1992). Expert and novice problem-solving behaviour in audit planning. Auditing: A Journal of Practice and Theory, 11, 1-20.

Benner, P. (1984). From Novice to Expert: Excellence and Power in Clinical Nursing Practice. Reading, Mass.: Addison-Wesley.

Betsch, T. (2005). Preference theory: An affect based approach to recurrent decision making. In T. Betsch, \& S. Haberstroh (Eds.), The routines of decision making (pp. 39-66). Mahwah, NJ: Lawrence Erlbaum.

Betsch, T., Haberstroh, S., Glöckner, A., Haar, T., \& Fiedler, K. (2001). The effects of routine strength on adaptation and information search in recurrent decision making. Organizational Behavior and Human Decision Processes, 84(1), 23-53.

Boshuizen, H. P. A., \& Schmidt, H. G. (1992). On the role of biomedical knowledge in clinical reasoning by experts, intermediates and novices. Cognitive Science, 16, 153-184.

Bröder, A. (2000). Assessing the empirical validity of the "Take-the-best" heuristic as a model of human probabilistic inference. Journal of Experimental Psychology: Learning, Memory, and Cognition, 26(5), 1332-1346.

Bröder, A. (2003). Decision making with the "adaptive toolbox": Influence of environmental structure, intelligence, and working memory load. Journal of Experimental Psychology: Learning, Memory, and Cognition, 29(4), 611-625.

Brunswik, E. (1955). Representative design and the probability theory in a functional psychology. Psychological Review, 62, 193-217.

Busemeyer, J. R., \& Townsend, J. T. (1993). Decision field theory: A dynamic-cognitive approach to decision making in an uncertain environment. Psychological Review, 100(3), 432-459. 
Büssing, A., \& Herbig, B. (2003). Implicit knowledge and experience in work and organizations. International Review of Industrial and Organizational Psychology, 18, 239-280.

Büssing, A., Herbig, B., \& Ewert, T. (2001). Implizites und explizites Wissen - Einflüsse auf Handeln in kritischen Situationen [Implicit and explicit knowledge - influences on action in critical situations]. Zeitschrift für Psychologie, 209, 174-200.

Chan, S. (1982). Expert judgements made under uncertainty: Some evidence and suggestions. Social Science Quarterly, 63, 428-444.

Chase, W. G., \& Simon, H. A. (1973a). The mind's eye in chess. In W. G. Chase (Ed.), Visual information processing (pp. 215 - 281). New York: Academic Press.

Chase, W. G., \& Simon, H. A. (1973b). Perception in chess. Cognitive Psychology, 1, 33-81.

Chi, M. T. H. (1978). Knowledge structure and memory development. In R. Siegler (Ed.), Children's thinking: What develops? (pp. 73-96). Hillsdale, NJ: Erlbaum.

Chi, M. T. H. (2006a). Two approaches to the study of experts' characteristics. In K. A. Ericsson, N. Charness, R. R. Hoffman, \& P. J. Feltovich (Eds.), The Cambridge handbook of expertise and expert performance (pp. 21-30). Cambridge: Cambridge University Press.

Chi, M. T. H. (2006b). Laboratory methods for assessing experts' and novices' knowledge. In K. A. Ericsson, N. Charness, R. R. Hoffman, \& P. J. Feltovich (Eds.), The Cambridge handbook of expertise and expert performance (pp. 167-184). Cambridge: Cambridge University Press.

Chi, M. T. H., Glaser, R., \& Rees, E. (1982). Expertise in problem solving. In R. Sternberg (Ed.), Advances in the psychology of Human Intelligence (Vol. 1, pp. 7-76). Hillsdale, NJ: Erlbaum.

Claessen, H. F., \& Boshuizen, H. P. A. (1985). Recall of medical information by students and doctors. Medical Education, 19, 61-67.

Crandall, B., \& Getchell-Reiter, K. (1993). Critical decision method: A technique for eliciting concrete assessment indicators from the intuition of NICY nurses. Advances in Nursing Science, 16, 42-51.

Curtis, B., Krasner, H., \& Iscoe, N. (1988). A field study of the software design process for large systems. Communications of the ACM, 31, 1268-1287.

Doherty, M. E., \& Kurz, E. M. (1996). Social judgment theory. Thinking \& Reasoning, 2(2-3), $109-140$.

Dougherty, M. R. P., Gettys, C. F., \& Ogden, E. E. (1999). MINERVA-DM: A memory processes model for judgments of likelihood. Psychological Review, 106(1), 180-209. 
Dreyfus, H. L., \& Dreyfus, S. E. (1986). Mind over Machine: The Power of Human Intuition and Expertise in the Era of Computer. New York: Free Press.

Ebbesen, E. B., \& Konečni, V. J. (1975). Decision making and information integration in the courts: the setting of bail. Journal of Personality and Social Psychology, 32, 805-821.

Egan, D. E., \& Schwartz, B. J. (1979). Chunking in the recall of symbolic drawings. Memory and Cognition, 7, 149-158.

Elstein, A. S., Shulman, L. S., \& Sprafka, S. A. (1978). Medical problem solving: An analysis of clinical reasoning. Cambridge, MA: Harvard University Press.

Englich, B., \& Mussweiler, T. (2001). Sentencing under uncertainty: Anchoring effects in the courtroom. Journal of Applied Social Psychology, 31, 1535-1551.

Epstein, S. (1990). Cognitive-experiential self-theory. In L. A. Pervin (Ed.), Handbook of personality: Theory and research (pp. 165-192). New York, NY: Guilford Press.

Ericsson, K. A., \& Charness, N. (1994). Expert performance: Its structure and acquisition. American Psychologist, 49, 725-747.

Ericsson, K. A., Charness, N., Hoffman, R. R., \& Feltovich, P. J. (Eds.). (2006). The Cambridge handbook of expertise and expert performance. Cambridge: Cambridge University Press.

Ericsson, K. A., \& Kintsch, W. (1995). Longterm working memory. Psychological Review, 102, 211-245.

Ericsson, K. A., Krampe, R. T., \& Tesch-Römer, C. (1993). The role of deliberate practice in the acquisition of expert performance. Psychological Review, 100, 363-406.

Ericsson, K. A., \& Lehmann, A. C. (1996). Expert and exceptional performance: Evidence of maximal adaptation to task constraints. Annual Review of Psychology, 47, 273-305.

Eteläpelto, A. (1993). Metacognition and the expertise of computer program comprehension. Scandinavian Journal of Educational Research, 37, 243-254.

Evans, J. S. B. T. (2008). Dual-processing accounts of reasoning, judgment, and social cognition. Annual Review of Psychology, 59, 255-278.

Feltovich, P. J., Prietula, M. J., \& Ericsson, K. A. (2006). Studies of expertise from psychological perspectives. In K. A. Ericsson, N. Charness, R. R. Hoffman, \& P. J. Feltovich (Eds.), The Cambridge handbook of expertise and expert performance (pp. 41-67). Cambridge: Cambridge University Press.

Flin, R., Slaven, G., \& Stewart, K. (1996). Emergency decision making in the offshore oil and gas industry. Human Factors, 38, 262-277. 
Frances, A., \& Ross, R. (2001). DSM-IV-TR ${ }^{T M}$ case studies: A clinical guide to differential diagnosis. Washington, DC: American Psychiatric Publishing.

Gaines, B. R., \& Shaw, M. L. G. (1993). Knowledge acquisition tools based on personal construct psychology. Knowledge Engineering Review, 8, 49-85.

Gigerenzer, G., \& Todd, P. M. (1999). Fast and frugal heuristics: The adaptive toolbox. In G. Gigerenzer, P. M. Todd, \& the ABC Group (Eds.), Simple heuristics that make us smart (pp. 3-34). New York: Oxford University Press.

Gilhooly, K. J., McGeorge, P., Hunter, J., Rawles, J. M., Kirby, I. K., Green, C., \& Wynn, V. (1997). Biomedical knowledge in diagnostic thinking: the case of electrocardiogram (ECG) interpretation. European Journal of Cognitive Psychology, 9, 199-223.

Glaser, R., \& Chi, M. T. H. (1988). Overview. In M. T. H. Chi, R. Glaser, \& M. J. Farr (Eds.), The nature of expertise (pp. xv-xxviii). Hillsdale, NJ: Erlbaum.

Glenberg, A. M., \& Epstein, W. (1987). Inexpert calibration of comprehension. Memory \& Cognition, 15, 84-93.

Glöckner, A. (2007). Does intuition beat fast and frugal heuristics? A systematic empirical analysis. In H. Plessner, C. Betsch, \& T. Betsch (Eds.), Intuition in Judgment and Decision Making (pp. 309-325). Mahwah, NJ: Lawrence Erlbaum

Glöckner, A. (2008). How evolution outwits bounded rationality: The efficient interaction of automatic and deliberate processes in decision making and implications for institutions. In C. Engel \& W. Singer (Eds.), Better than conscious? Decision making, the human mind, and implications for institutions (pp. 259-284). Cambridge, MA: MIT Press.

Glöckner, A., \& Betsch, T. (2008a). Multiple-reason decision making based on automatic processing. Journal of Experimental Psychology: Learning, Memory, and Cognition, 34(5), 1055-1075.

Glöckner, A., \& Betsch, T. (2008b). Modeling option and strategy choices with connectionist networks: Towards an integrative model of automatic and deliberate decision making. Judgment and Decision Making, 3, 215-228.

Glöckner, A., \& Betsch, T. (2008c). Do people make decisions under risk based on ignorance? An empirical test of the Priority Heuristic against Cumulative Prospect Theory. Organizational Behavior and Human Decision Processes, 107(1), 75-95.

Glöckner, A., Betsch, T., \& Schindler, N. (under review). Coherence shifts in probabilistic inference tasks. Manuscript submitted for publication.

Gruber, H. (1999). Erfahrung als Grundlage kompetenten Handelns. Bern: Huber. 
Hacker, W. (1992). Expertenkönnen: Erkennen und Vermitteln. Göttingen: Verlag für Angewandte Psychologie.

Hacker, W., \& Matern, B. (1980). Methoden zum Ermitteln tätigkeitsregulierender kognitiver Prozesse und Repräsentationen bei industriellen Arbeitstätigkeiten. In W. Volpert (Hrsg.), Beiträge zur psychologischen Handlungstheorie (S. 29-49). Bern: Huber.

Hacker, W., \& Vaic, H. (1973). Psychologische Analyse interindividueller Leistungsdifferenzen als eine Grundlage von Rationalisierungsbeiträgen. In W. Hacker, W. Quaas, H. Raum, \& H. J. Schulz (Hrsg.), Psychologische Arbeitsuntersuchung (S. 109-131). Berlin: Deutscher Verlag der Wissenschaften.

Hammond, K. R., Hamm, R. M., Grassia, J., \& Pearson, T. (1987). Direct comparison of the efficacy of intuitive and analytical cognition in expert judgment. IEEE Transactions on Systems, Man, \& Cybernetics, 17(5), 753-770.

Hatano, G., \& Inagaki, K. (2000). Knowledge acquisition and use in higher-order cognition. In K. Pawlik, \& M. R. Rosenzweig (Eds.), International Handbook of Psychology (pp. 167190). Thousand Oaks, CA: Sage.

Herbig, B. (2001). Vergleichende Untersuchung von Struktur und Inhalt expliziten und impliziten Wissens im Arbeitskontext. Aachen: Shaker.

Herbig, B., \& Büssing, A. (2003). Comparison of the role of explicit and implicit knowledge in working. Psychology Science, 45 (III), 165-188.

Herbig, B., Büssing, A., \& Ewert, T. (2001). The role of tacit knowledge in the work context of nursing. Journal of Advanced Nursing, 34, 687-695.

Hershey, D. A., Walsh, D. A., Read, S. J., \& Chulef, A. S. (1990). The effects of expertise on financial problem solving: Evidence for goal-directed, problem-solving scripts. Organizational Behavior and Human Decision Processes, 46, 77-101.

Hoffman, R. R. (1987). The problem of extracting the knowledge of experts from the perspective of experimental psychology. The AI Magazine, 8, 53-67.

Hoffman, R. R. (1998). How can expertise be defined? Implications of research from cognitive psychology. In R. Williams, W. Faulkner, \& J. Fleck (Eds.), Exploring expertise (pp. 81100). New York: Macmillan.

Hoffman, R. R., Shadbolt, N. R., Burton, A. M., \& Klein, G. (1995). Eliciting knowledge from experts: A methodological analysis. Organizational Behavior and Human Decision Processes, 62, 129-158.

Holyoak, K. J., \& Simon, D. (1999). Bidirectional reasoning in decision making by constraint satisfaction. Journal of Experimental Psychology: General, 128, 3-31. 
Holyoak, K. J., \& Spellman, B. A. (1993). Thinking. Annual Review of Psychology, 44, 265-315.

Huber, O., \& Huber, O. W. (2008). Gambles vs. quasi-realistic scenarios: Expectations to find probability and risk-defusing information. Acta Psychologica, 127, 222-236.

Huber, O., Wider, R., \& Huber, O. W. (1997). Active information search and complete information presentation in naturalistic risky decision tasks. Acta Psychologica, 95, 15-29.

Huber, O. W. (2007). Active search for probability information and recall performance: Is probability an outstanding element in the mental representation of risky decisions? In M. Abdellaoui, R. D. Luce, M. J. Machina, \& B. Munier (Eds.), Uncertainty and risk: mental, formal, experimental representations (pp. 261-274). Berlin: Springer.

Johnson, K. E., \& Mervis, C. B. (1997). Effects of varying levels of expertise on the basic level of categorization. Journal of Experimental Psychology: General, 126, 248-277.

Juslin, P., Winman, A., \& Hansson, P. (2007). The naive intuitive statistician: A naive sampling model of intuitive confidence intervals. Psychological Review, 114(3), 678-703.

Kahneman, D., \& Frederick, S. (2002). Representativeness revisited: Attribute substitution in intuitive judgment. In T. Gilovich, D. Griffin, \& D. Kahneman (Eds.), Heuristics and biases: The psychology of intuitive judgment (pp. 49-81). New York: Cambridge University Press.

Kahneman, D., Slovic, P., \& Tversky, A. (Eds.). (1982). Judgement under uncertainty: Heuristics and biases. New York: Cambridge University Press.

Kahneman, D., \& Tversky, A. (1982). The psychology of preferences. Scientific American, 246, 160-173.

Kahneman, D., \& Tversky, A. (1984). Choices, values, and frames. American Psychologist, 39, 341-350.

Kirschenbaum, S. S. (1992). Influence of experience on information-gathering strategies. Journal of Applied Psychology, 77, 343-352.

Klein, G. A. (1989). Recognition-primed decisions. In W. B. Rouse (Ed.), Advances in manmachine systems research (Vol. 5, pp. 47-92). Greenwich, CT: JAI Press.

Klein, G. A., Orasanu, J., Calderwood, R., \& Zsambok, C. E. (Eds.). (1993). Decision making in action: Models and methods. Norwood, NJ: Ablex.

Klemp, G. O., \& McClelland, D. C. (1986). What characterizes intelligent functioning among senior managers? In R. J. Sternberg, \& R. K. Wagner (Eds.), Practical Intelligence: Nature and origin of competence in everyday world (pp. 31-50). Cambridge: Cambridge University Press. 
Koubek, R. J., \& Salvendy, G. (1991). Cognitive performance of super-experts on computer program modification tasks. Ergonomics, 34, 1095-1112.

Larkin, J. H., McDermott, J., Simon, D. P., \& Simon, H. A. (1980). Models of competence in solving physics problems. Cognitive Science, 4, 317-345.

Leersch, H.-J. (August 8th, 2001). Diagnose: Kommissionitis. Die Welt.

Leithwood, K., \& Steinbach, R. (1995). Expert problem solving: Evidence from school and district leaders. Albany, NY: State University of New York Press.

Lesgold, A. M., Rubinson, H., Feltovich, P., Glaser, R. Klopfer, D., \& Wang, Y. (1988). Expertise in complex skills: Diagnosing X-ray pictures. In M. T. H. Chi, R. Glaser, \& M. J. Farr (Eds.), The Nature of Expertise (pp. 311-342). Hillsdale, NJ: Erlbaum.

Lind, G., \& Sandmann, A. (2003). Lernstrategien und Domänenwissen [Learning strategies and domain-specific knowledge]. Zeitschrift für Psychologie, 211, 171-192.

McClelland, J. L., \& Rumelhart, D. E. (1981). An interactive model of context effects in letter perception. Part 1. An account of basic findings. Psychological Review, 88, 375-407.

Meehl, P. E. (1954). Clinical versus statistical prediction: A theoretical analysis and a review of the evidence. Minneapolis: University of Minnesota Press.

Müller, A., Herbig, B., \& Petrovic, K. (2007). Die systematische Unterstützung der Innovativität von Arbeitsgruppen [Systematic support for innovation in work groups]. Wirtschaftspsychologie, 2, 83-92.

Müller, A., Herbig, B., \& Petrovic, K. (in press). The explication of implicit team knowledge and its supporting effect on team processes and technical innovations. An action regulation perspective on team reflexivity. Small Group Research.

Muzzin, L. J., Norman, G. R., Feightner, J. W., \& Tugwell, P. (1983). Expertise in recall of clinical protocols in two specialty areas. In Proceedings of the 22nd Conference on Research in Medical Education (pp. 122-128). Washington, DC: American Association of Medical Colleges.

Newell, B. R. (2005). Re-Visions of rationality? Trends in Cognitive Sciences, 9(1), 11-15.

Oesterreich, R., \& Volpert, W. (1987). Handlungstheoretisch orientierte Arbeitsanalyse. In J. Rutenfranz, \& U. Kleinbeck (Hrsg.), Enzyklopädie der Psychologie D III (Bd. 1 Arbeitspsychologie, S. 43-73). Göttingen: Hogrefe.

Önkal-Atay, D., Yates, J. F., Şimga-Mugan, C., \& Ötzin, Ş. (2003). Professional vs. amateur judgement accuracy: the case of foreign exchange rates. Organizational Behavior and Human Decision Processes, 91, 169-185. 
Pascual, R., \& Henderson, S. (1997). Evidence of naturalistic decision making in military command and control. In C. E. Zsambok, \& G. Klein (Eds.), Naturalistic Decision Making (pp. 217-226). Mahwah, NJ: Erlbaum.

Patel, V. L., Arocha, J. F., \& Zhang, J. (2005). Thinking and reasoning in medicine. In K. J. Holyoak, \& R. G. Morrison (Eds.), The Cambridge Handbook of Thinking and Reasoning (pp. 727-750). Cambridge: Cambridge University Press.

Patel, V. L., Evans, A. E., \& Groen, G. J. (1989). Biomedical knowledge and clinical reasoning. In D. A. Evans, \& V. L. Patel (Eds.), Cognitive science in medicine: Biomedical modeling (pp. 53-112). Cambridge, MA: MIT Press.

Patel, V. L., \& Kaufman, D. R. (1995). Clinical reasoning and biomedical knowledge: implications for teaching. In J. Higgs, \& M. Jones (Eds.), Clinical reasoning in the health professions (pp. 117-128). Oxford: Butterworth-Heinemann Ltd.

Payne, J. W., Bettman, J. R., \& Johnson, E. J. (1988). Adaptive strategy selection in decision making. Journal of Experimental Psychology: Learning, Memory, and Cognition, 14, 534552.

Payne, J. W., Bettman, J. R., \& Johnson, E. J. (1993). The adaptive decision maker. Cambridge: Cambridge University Press.

Polanyi, M. (1966). The tacit dimension. New York: Doubleday.

Pomplun, M., Ritter, H., \& Velichkovsky, B. (1996). Disambiguating complex visual information: Towards communication of personal views of a scene. Perception, 25(8), 931-948.

Ramsauer, P. (July 4th, 2000). Wider die Kommissionitis. Die Welt.

Randel, J. M., Pugh, H. L., \& Reed, S. K. (1996). Differences in expert and novice situation awareness in naturalistic decision making. International Journal of Human-computer Studies, 45, 579-597.

Read, S. J., Vanman, E. J., \& Miller, L. C. (1997). Connectionism, Parallel constraint satisfaction processes, and Gestalt principles: (Re)introducing cognitive dynamics to social psychology. Personality and Social Psychology Review, 1, 26-53.

Rieskamp, J., \& Otto, P. E. (2006). SSL: A Theory of How People Learn to Select Strategies. Journal of Experimental Psychology: General, 135(2), 207-236.

Ross, K. G., Shafer, J. L., \& Klein, G. (2006). Professional judgements and „Naturalistic Decision Making“. In K. A. Ericsson, N. Charness, R. R. Hoffman, \& P. J. Feltovich (Eds.), The Cambridge handbook of expertise and expert performance (pp. 403-419). Cambridge: Cambridge University Press. 
Rumelhart, D. E., \& McClelland, J. L. (1982). An interactive activation model of context effects in letter perception: II. The contextual enhancement effect and some tests and extensions of the model. Psychological Review, 89, 60-94.

Salas, E., \& Klein, G. (Eds.). (2001). Linking expertise and Naturalistic Decision Making. Mahwah, NJ: Erlbaum.

Schaper, N., \& Sonntag, K. (1998). Analysis and training of diagnostic expertise in complex technical domains. European Journal of Work and Organizational Psychology, 7, 479-499.

Schaub, H., \& Strohschneider, S. (1992). Die Auswirkungen unterschiedlicher Problemlöseerfahrung mit einem unbekannten komplexen Problem. Zeitschrift für Arbeits- und Organisationspsychologie, 36, 117-126.

Schenk, K. D., Vitalari, N. P., \& Davis, K. S. (1998). Differences between novices and expert system analysts: What do we know and what do we do? Journal of Management in Information Systems, 15, 9-50.

Schmidt, H. G., \& Boshuizen, H. P. A. (1993). On the origin of intermediate effects in clinical case recall. Memory \& Cognition, 21, 338-351.

Schneider, W. (1985). Training high performance skills: Fallacies and guidelines. Human Factors, $27,285-300$.

Sentker, A. (April 17th, 2008). Pflichtlektüre. Ein neuer Beziehungsratgeber für Forscher und Politiker. Die Zeit, 17, 35.

Shanteau, J. (1992). Competence in experts: the role of task characteristics. Organizational Behavior and Human Decision Processes, 53, 252-266.

Simon, D. (2004). A third view on the black box: Cognitive Coherence in legal decision making. University of Chicago Law Review, 71, 511-586.

Simon, D., Krawczyk, D. C., \& Holyoak, K. J. (2004). Construction of preferences by constraint satisfaction. Psychological Science, 15, 331-336.

Simon, D., Snow, C. J., \& Read, S. J. (2004). The redux of cognitive consistency theories: Evidence judgments by constraint satisfaction. Journal of Personality and Social Psychology, $86,814-837$.

Simon, H. A. (1955). A behavioural model of rational choice. The Quarterly Journal of Economics, 69, 99-118.

Simon, H. A. (1956). Rational choice and the structure of the environment. Psychological Review, 63, 129-138. 
Simon, H. A. (1982). Models of bounded rationality. Cambridge, MA: MIT Press.

Simon, H. A., \& Chase, W. G. (1973). Skill in chess. American Scientist, 61, 394-403.

Sloman, S. A. (2002). Two systems of reasoning. In T. Gilovich, D. Griffin, \& D. Kahneman (Eds.), Heuristics and biases: The psychology of intuitive judgment (pp. 379-396). New York, NY: Cambridge University Press.

Sonnentag, S. (1998). Expertise in professional software design: A process study. Journal of Applied Psychology, 83, 703-715.

Sonnentag, S. (2000). Expertise at work: Experience and excellent performance. International Review of Industrial and Organizational Psychology, 15, 223-264.

Speelman, C. (1998). Implicit expertise: Do we expect too much from our experts? In K. Kirsner, C. Speelman, M. Maybery, A. O’Brien-Malone, M. Anderson, \& C. MacLeod (Eds.), Implicit and explicit mental processes (pp. 135-147). Mawah, NJ: Erlbaum.

Spellman, B. A. (in press). Judges, Expertise, and Analogy. In D. Klein \& G. Mitchell (Eds.), The Psychology of Judicial Decision Making. Oxford: Oxford University Press.

Sujan, H., Sujan, M., \& Bettman, J. R. (1988). Knowledge structure differences between more effective and less effective salespeople. Journal of Marketing Research, 25, 81-86.

Thagard, P., \& Millgram, E. (1995). Inference to the best plan: A coherence theory of decision. In A. Ram \& D. B. Leake (Eds.), Goal-driven learning (pp. 439-454). Cambridge, MA: MIT Press.

Tversky, A., \& Kahneman, D. (1974). Judgment under uncertainty: Heuristics and biases. Science, 185(4157), 1124-1131.

Visser, W. (1994). Organisation of design activities: Opportunistic, with hierarchical episodes. Interacting with computers, 6, 239-274.

Voss, J. F., Greene, T. R., Post, T., \& Penner, B. C. (1983). Problem-solving skill in the social sciences. In G. Bower (Ed.), The psychology of learning and motivation (pp. 165-213). New York: Academic Press.

Wagner, R. K., \& Sternberg, R. J. (1985). Practical intelligence in real-world pursuits: The role of tacit knowledge. Journal of Personality and Social Psychology, 49, 436-458.

Wertheimer, M. (1925). Über Gestalttheorie. Philosophische Zeitschrift für Forschung und Aussprache, 1, 39-60. 
Wertheimer, M. (1938). Laws of organization in perceptual forms. In W. D. Ellis (Ed.), A source book of Gestalt psychology (pp. 71-88). London: Kegan Paul, Trench, Trubner \& Company Print.

Wiedemann, J. (1995). Ermittlung von Qualifizierungsbedarf-am Beispiel der Störungsdiagnose in der flexiblen Fertigung. Münster: Waxmann.

Wiggins, M., \& O'Hare, D. (1995). Expertise in aeronautical weather-related decision making: A cross-sectional analysis of general aviation pilots. Journal of Experimental Psychology: Applied, 1, 305-320.

Williams, D. J., \& Noyes, J. M. (2007). Effect of experience and mode of presentation on problem solving. Computers in Human Behavior, 23, 258-274.

Winkel, G. H. (1987). Implications of environmental context for validity assessments. In D. Stokols, \& I. Altman (Eds.), Handbook of environmental psychology, 1 (pp. 71-97). New York: Wiley.

Witteman, C. L. M., \& van der Bercken, J. H. L. (2007). Intermediate effects in psychodiagnostic classification. European Journal of Psychological Assessment, 23, 56-61.

Yates, J. F., \& Tschirhart, M. D. (2006). Decision-making expertise. In K. A. Ericsson, N. Charness, R. R. Hoffman, \& P. J. Feltovich (Eds.), The Cambridge handbook of expertise and expert performance (pp. 421-438). Cambridge: Cambridge University Press. 